\title{
Late Adverse Effect
}

National Cancer Institute

\section{Source}

National Cancer Institute. Late Adverse Effect. NCI Thesaurus. Code C4808.

Any symptom or condition which is a result of a medical intervention but arises months

or years after it. 